\title{
Sobrevivência de Micélio e Escleródios de Rhizoctonia solani Tratados com Trichoderma spp., em Restos de Cultura de Eucalyptus sp.
}

\author{
Sandra Kunieda-Alonso ${ }^{1}$, Acelino C. Alfenas ${ }^{2} \&$ Luiz A. Maffia ${ }^{3}$ \\ Departamento de Fitopatologia, Universidade Federal de Viçosa, CEP 36570-000, Viçosa, MG, fax: (31) 3899-2240;

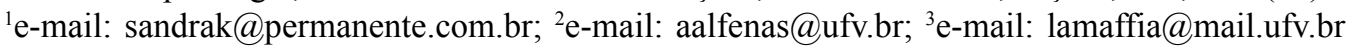

(Aceito para publicação em 18/10/2004)

Autor para correspondência: Acelino Couto Alfenas

KUNIEDA-ALONSO, S., ALFENAS, A.C. \& MAFFIA, L.A. Sobrevivência de micélio e escleródios de Rhizoctonia solani tratados com Trichoderma spp., em restos de cultura de Eucalyptus sp. Fitopatologia Brasileira 30:164-168. 2005.

\section{RESUMO}

Este trabalho objetivou estudar a sobrevivência de micélio e escleródios de Rhizoctonia solani AG1-1C, em restos de cultura de eucalipto (Eucalyptus spp.) e avaliar a eficiência dos isolados Trichoderma longibrachiatum (UFV-1) e T. inhamatum (UFV-2 e UFV-3), comprovadamente antagônicos a $R$. solani, em reduzir a sobrevivência do patógeno, em condições de campo. Ao longo de 12 meses de avaliação, a sobrevivência de $R$. solani em folhas de eucalipto infetadas não foi afetada por fatores ambientes e tampouco por possíveis antagonistas de ocorrência natural. Por outro lado, a sobrevivência dos escleródios decresceu progressivamente, atingindo cerca de $26 \%$. Não se constatou influência dos isolados de Trichoderma spp. na sobrevivência de $R$. solani em folhas infetadas de eucalipto. Entretanto, redução significativa e contínua na viabilidade de escleródios, foi observada, equiparando-se ao tratamento com fungicida, aos 25 dias após inoculação dos antagonistas, sendo os três isolados igualmente efetivos. Já, a sobrevivência no tratamento com fungicida, atingiu níveis significativamente baixos na primeira avaliação, mas sua eficiência foi reduzida ao longo do período experimental. Redução progressiva e contínua na sobrevivência de escleródios da testemunha foi também constatada, mas inferior a quaisquer dos tratamentos.

Palavras-chave adicionais: queima de folhas, controle biológico, restos culturais.

\begin{abstract}
Survival of Rhizoctonia solani mycelia and sclerotia treated with Trichoderma spp., in Eucalypltus sp. litter

The survival of mycelium and sclerotia of Rhizoctonia solani AG1-1C was studied in Eucalyptus sp. litter treated with the antagonists Trichoderma longibrachiatum (UFV-1) and T. inhamatum (UFV-2 and UFV-3) isolates. For 12 months, $R$. solani survival in Rhizoctonia infected eucalypt leaves, was apparently not affected by environmental factors, nor by possible naturally occurring antagonists. On the other hand, the sclerotial rate survival decreased progressively reaching $26 \%$. The influence of Trichoderma spp. isolates did not affect $R$. solani survival in eucalypt-infected leaves, but significant and continuous reduction of sclerotia viability was observed when compared to captan treatment, 25 days after treatment with the antagonists. The survival in the fungicide treatment reached significantly low levels in the first evaluation, but its efficiency decreased with time. Progressive reduction and continuous survival of sclerotia was detected in the control as well, but significantly less than any other treatment.
\end{abstract}

Additional keywords: leaf bligth, byological control, litter.

Rhizoctonia solani Kühn (Thanatephorus cucumeris (Frank) Donk é um dos principais patógenos que ocorrem na cultura do eucalipto (Eucalyptus spp.). Em plantios comerciais, $R$. solani incide inicialmente sobre as folhas de ramos rasteiros, por meio de crescimento micelial epifítico a partir de solo infestado. Posteriormente, ataca as folhas de ramos superiores, causando a queima ascendente na copa. $\mathrm{O}$ espaçamento reduzido entre plantas, a irrigação e o intenso crescimento vegetativo de mudas em viveiro favorecem a disseminação e a multiplicação do patógeno, que causa a queima de folhas. Brotações, contendo micélio e escleródios do patógeno, podem constituir fonte de inóculo às estacas para enraizamento (Alfenas et al., 2004). A habilidade saprofítica competitiva, o potencial patogênico e a vasta gama de hospedeiros tornam $R$. solani um patógeno economicamente importante (Menzies, 1970). O fungo sobrevive no solo e em restos de cultura na forma micelial ou esclerodial. A eliminação de plantas mortas infetadas, folhas e ramos doentes e a coleta seletiva de brotos sadios, em jardins e minijardins clonais a céu aberto, constituem medidas de controle da mela de estacas para enraizamento (Silveira et al., 2003; Alfenas et al., 2004). No entanto, essas medidas, 
Sobrevivência de micélio e escleródios de Rhizoctonia solani tratados...

embora reduzam a quantidade de inóculo, não eliminam o patógeno no solo ou substrato. Este pode ser levado às brotações por respingos de água e dispersão de partículas do solo infestado (Alfenas et al., 2004). A pulverização de fungicidas em restos culturais de eucalipto infetados não erradica o patógeno, por não atingir grande parte das estruturasvoltadas para o solo e, em particular, por ser ineficiente contra escleródios (Silveira et al., 2003). Além disso, não se conhece o efeito dos fungicidas sobre a possível flora antagonista natural e nem o registro de produtos para utilização na cultura do eucalipto. Desse modo, o controle biológico pode tornar-se uma estratégia viável de manejo da doença.

Dentre os fungos utilizados em programas de controle biológico de doença de plantas, destacam-se muitas espécies do gênero Trichoderma Pers. que parasitam hifas e escleródios de Rhizoctonia sp. (Mukherjee et al., 1995), e podem reduzir sua sobrevivência.

O uso de fungicidas e a limpeza fitossanitária em viveiro de eucalipto não são suficientes para erradicar o inóculo do patógeno. Assim, este trabalho objetivou estudar a longevidade de micélio e escleródios de $R$. solani, em restos de cultura de eucalipto e avaliar a eficiência dos isolados $T$. longibrachiatum Rifai (UFV-1) e T. inhamatum Veerkamp \& Gams (UFV-2 e UFV-3), comprovadamente antagônicos a $R$. solani, em reduzir a sobrevivência do patógeno, em condições de campo.

Utilizou-se um isolado de $R$. solani, AG1-1C (RH15), obtido de folhas de eucalipto com sintoma de queima. Para a produção de escleródios, micélio do patógeno foi triturado em água desionizada esterilizada $(1 \mathrm{~g} / \mathrm{l}) \mathrm{em}$ um homogeneizador tipo Polytron, modelo PT 10/35 (Brinkman Instruments $\AA$ ), velocidade 4 , durante 1 min. Feixes com cerca de dez ramos com folhas de eucalipto foram desinfestados por imersão em solução de hipoclorito de sódio a $0,1 \%$. Em seguida, os ramos foram imersos na suspensão micelial e colocados em câmara de nevoeiro a $25+2{ }^{\circ} \mathrm{C}$ e fotoperíodo de $12 \mathrm{~h}$. Após 12 dias, os ramos foram retirados e secos ao ar, no interior da casa de vegetação.

Ramos com escleródios e folhas contendo lesões de $R$. solani foram acondicionados, separadamente, em saquinhos brancos de náilon $(10 \times 10 \mathrm{~cm})$, malha $2 \mathrm{~mm}$. Estes foram levados para a área de multiplicação clonal de eucalipto, em Viçosa, MG, onde foram colocados em contato com restos de poda das cepas (tocos de árvores após o corte). $\mathrm{O}$ ensaio foi montado em blocos casualizados, com três blocos de 12 saquinhos de náilon cada. Os 12 saquinhos destinaram-se à amostragem destrutiva por 12 meses. A sobrevivência do patógeno foi avaliada mediante plaqueamento de escleródios e fragmentos de folhas em ágar-água a $2 \%$, contendo $1 \mathrm{ppm}$ de benomyl, para evitar-se a interferência de fungos antagonistas e saprófitas, nas avaliações. Semearam-se 100 escleródios de cada um dos três blocos de cada tratamento. Após $48 \mathrm{~h}$ de incubação, a $25^{\circ} \mathrm{C}$, no escuro, efetuou-se a contagem de colônias de $R$. solani emergentes dos fragmentos das folhas lesionadas e a partir de escleródios. As avaliações foram realizadas mensalmente, durante 12 meses, de dezembro de 1994 a novembro de 1995. A média das temperaturas máxima e mínima, a aproximadamente $500 \mathrm{~m}$ da área experimental foi de $31,37^{\circ} \mathrm{C}$ e $9,74{ }^{\circ} \mathrm{C}$, nos meses de janeiro e junho de 1995, respectivamente. A média de insolação diária/ mês foi de $11,75 \mathrm{~h}$ e a precipitação anual foi de $1102,1 \mathrm{~mm}$, concentrada nos meses de dezembro/94 a março/95 e outubro a novembro/95. A umidade relativa do ar foi de 69,71 a $85,26 \%$.

Em outro ensaio, folhas lesionadas e ramos contendo escleródios de $R$. solani foram imersos, separadamente, em 2 1 de suspensão conidial $\left(10^{6}\right.$ conídios $\left./ \mathrm{ml}\right)$ dos isolados UFV-1 (T. longibrachiatum) e UFV-2 e UFV-3 (T. inhamatum), durante 3 min. Após remoção do excesso de suspensão de inóculo sobre papel-toalha, secções de ramos com escleródios e folhas lesionadas foram colocadas separadamente em saquinhos brancos de náilon. Folhas e secções de ramos, imersos por 3 min, na mistura de captan (1200 ppm) + hipoclorito de sódio (800 ppm de $\mathrm{Cl}_{2}$ ), contendo adjuvante (Extravon a 0,05\%) (Silveira et al., 1992) e amostras infetadas sem tratamento com fungicida ou com antagonista, foram analogamente acondicionadas em saquinhos de náilon para servirem como testemunha. Os saquinhos, contendo as amostras, foram mantidos entre restos de ramos e folhas de eucalipto, sob condições de jardim clonal, em Viçosa, MG, no período de 01 a 30/12/1994. Empregou-se o delineamento de blocos casualizados com quatro blocos e cinco repetições. A cada seis dias, avaliou-se a sobrevivência do patógeno, como descrito. A média das temperaturas máxima e mínima, a aproximadamente $500 \mathrm{~m}$ da área experimental, foi de $28,63{ }^{\circ} \mathrm{C}$ e $18,25{ }^{\circ} \mathrm{C}$. A insolação média diária foi de $6,1 \mathrm{~h}$, sendo a precipitação mensal de $283,5 \mathrm{~mm}$. A umidade relativa do ar foi de 69,7 a $96 \%$.

A sobrevivência de $R$. solani na forma de micélio em folhas lesionadas de eucalipto, aparentemente, não foi afetada por fatores ambientes e tampouco por possíveis antagonistas de ocorrência natural. Ao longo de 12 meses de avaliação, todos os fragmentos foliares plaqueados originaram colônias de Rhizoctonia sp. Por outro lado, a sobrevivência dos escleródios decresceu progressivamente, havendo queda brusca na sua viabilidade, atingindo $59 \%$ ao final do primeiro mês. Do segundo mês até a última avaliação, a redução na viabilidade dos escleródios foi suave, à taxa mensal de 4 a 7\%, atingindo cerca de $26 \%$ ao final dos 12 meses (Figura 1).

Boosalis \& Scharen (1959) observaram que o micélio deste fungo sobrevive em fragmentos de beterraba, como hifa de coloração marrom-escura e irregularmente ramificada, no interior dos tecidos do hospedeiro por até sete meses após a colheita. Em raízes infetadas de beterraba, $R$. solani AG-2-2 sobreviveu pelo menos por um ano (Ruppel, 1991). Baird (1993) determinou que o fungo pode sobreviver em resíduos do cultivo de amendoim (Arachis hypogaea L.) deixados sobre o solo após a colheita. Neste trabalho, micélio de $R$. solani permaneceu viável por, até, 12 meses em folhas de eucalipto lesionadas.

A maioria dos estudos de sobrevivência de escleródios envolve o enterrio dos mesmos em solos, com resultados variáveis. Manian \& Manibhushanrao (1993) determinaram 
A. Kunieda-Alonso et al.

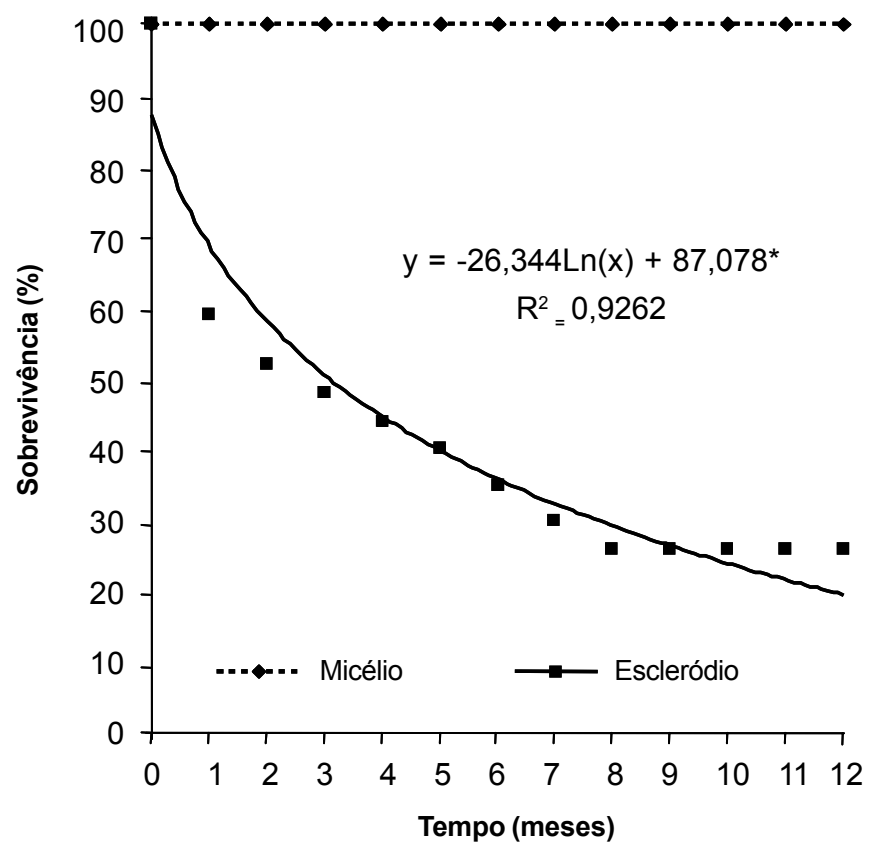

FIG. 1 - Sobrevivência de micélio e escleródios de Rhizoctonia solani AG1-1C (RH-15), entre restos culturais de eucalipto (Eucalyptus spp.). * Significativo pelo Teste F a $0,5 \%$.

que em solos úmidos, os escleródios foram viáveis por até 21 meses do enterrio, a temperaturas entre 20 e $32{ }^{\circ} \mathrm{C}$. Segundo Gadd \& Bertus (1928) citados por Park (1970), escleródios de $R$. solani podem sobreviver até seis anos em solo seco ao ar. Entretanto, quando os escleródios são totalmente expostos ao ambiente, o período de viabilidade é reduzido (Venkatasubbaiah \& Safeeulla, 1983). Escleródios expostos ao sol durante cerca de $6 \mathrm{~h}$ diárias permaneceram viáveis por até 57 dias, dependendo do isolado (Sherwood, 1970). A área de multiplicação clonal onde se instalou o presente ensaio, recebeu, em média, mais de $6 \mathrm{~h}$ diárias de sol, exceto nos meses de maio, outubro e novembro de 1995. Entretanto, os restos de ramos e folhas e os próprios saquinhos de náilon evitaram a exposição solar direta nos escleródios. Cerca de $26 \%$ dos escleródios permaneceram viáveis nas condições do ensaio, podendo sobreviver por períodos superiores a 12 meses. A germinação de escleródios pode variar com a idade, sendo os mais jovens de maior poder germinativo (Naiki, 1985). Isso pode explicar a redução progressiva na germinação ao longo do experimento. Segundo Bruehl (1987), fungos de solo têm maior capacidade de sobrevivência na forma esclerodial que micelial, contrariamente ao observado neste trabalho. Entretanto, Bruehl (1987) referiu-se a hifas livres no solo, não àquelas no interior de tecidos. Segundo Naiki (1985), quando ocorre falha na germinação de escleródios em meio de ágarágua não significa necessariamente que estejam mortos. $\mathrm{O}$ contato com raízes do hospedeiro pode induzir germinação de escleródios que possuem poucas células intactas. Portanto, sobre o hospedeiro, a percentagem de germinação de escleródios de $R$. solani pode ser superior à encontrada, neste trabalho, em ágar-água.
Não se constatou influência dos antagonistas na sobrevivência de $R$. solani na forma micelial. Todos os fragmentos de folhas lesionadas, quando plaqueados, originaram colônias do patógeno. Por outro lado, observou-se redução significativa e contínua na viabilidade de escleródios, equiparando-se ao tratamento fungicida, aos 25 dias após inoculação dos antagonistas, sendo os três isolados igualmente efetivos (Figura 2). Já, a sobrevivência no tratamento com fungicida, atingiu níveis significativamente baixos na primeira avaliação e o fungicida teve sua eficiência reduzida ao longo do período experimental. Sobre os escleródios plaqueados nãogerminados, observou-se esporulação de Trichoderma sp. Redução progressiva e contínua na sobrevivência de escleródios da testemunha foi também constatada, mas significativamente inferior a quaisquer dos tratamentos.

Segundo Mukherjee et al. (1995), T. harzianum parasita hifas e escleródios de R. solani, sendo mais efetivo no parasitismo das primeiras. O micoparasitismo de $T$. harzianum (Jaffee, 1993) e T. longibrachiatum (Melo, 1996) tem sido observado por vários pesquisadores, em hifas de $R$. solani. A inibição do crescimento de $R$. solani ocorre logo após o contato com o antagonista, seguindo-se uma série de eventos de degradação da hifa hospedeira (Benhamou \& Chet, 1993). Entretanto, neste trabalho, nenhum dos antagonistas utilizados reduziu a sobrevivência de $R$. solani na forma micelial em folha lesionada. Isso ocorreu, provavelmente, pela incapacidade de Trichoderma spp. em hiperparasitar o micélio do patógeno no interior dos tecidos foliares, protegido pelo mesófilo. Aparentemente, não há trabalhos sobre o micoparasitismo de Trichoderma spp. sobre micélio de $R$. solani, em tecidos do hospedeiro. O micoparasitismo, sempre que detectado, ocorreu sobre micélio livre, estando este totalmente exposto à ação dos antagonistas.

Ao contrário do encontrado para micélio, os antagonistas reduziram a sobrevivência dos escleródios do patógeno. Esses se encontravam na superfície externa de ramos e folhas de eucalipto, completamente expostos aos antagonistas e sujeitos às oscilações de umidade do ar, temperatura, precipitação pluviométrica e insolação. Acreditase que as variações de ambiente, especialmente a insolação, podem ter afetado a sobrevivência dos escleródios, uma vez que aqueles não tratados também tiveram sua viabilidade reduzida ao longo do experimento. Segundo Sherwood (1970), 183 horas de insolação direta são suficientes para erradicar escleródios de $R$. solani. A insolação total acumulada foi de 190 h, durante a condução do presente trabalho. Todavia, os saquinhos de náilon contendo escleródios, bem como os restos de cultura sobre os saquinhos, não permitiram sua exposição direta aos raios solares, o que impossibilitou uma avaliação da insolação real nos escleródios.

Têm-se relatado micoparasitismo e outros efeitos antagonísticos de microrganismos do solo sobre a germinação de escleródios e sobrevivência de $R$. solani (Naiki, 1985). Segundo Beagle-Ristaino \& Papavizas (1985), T. viride Pers., T. harzianum Rifai, T. hamatum (Bon.) Bain e Thrichoderma virens (Miller et al.) Arx colonizaram escleródios de R. solani 


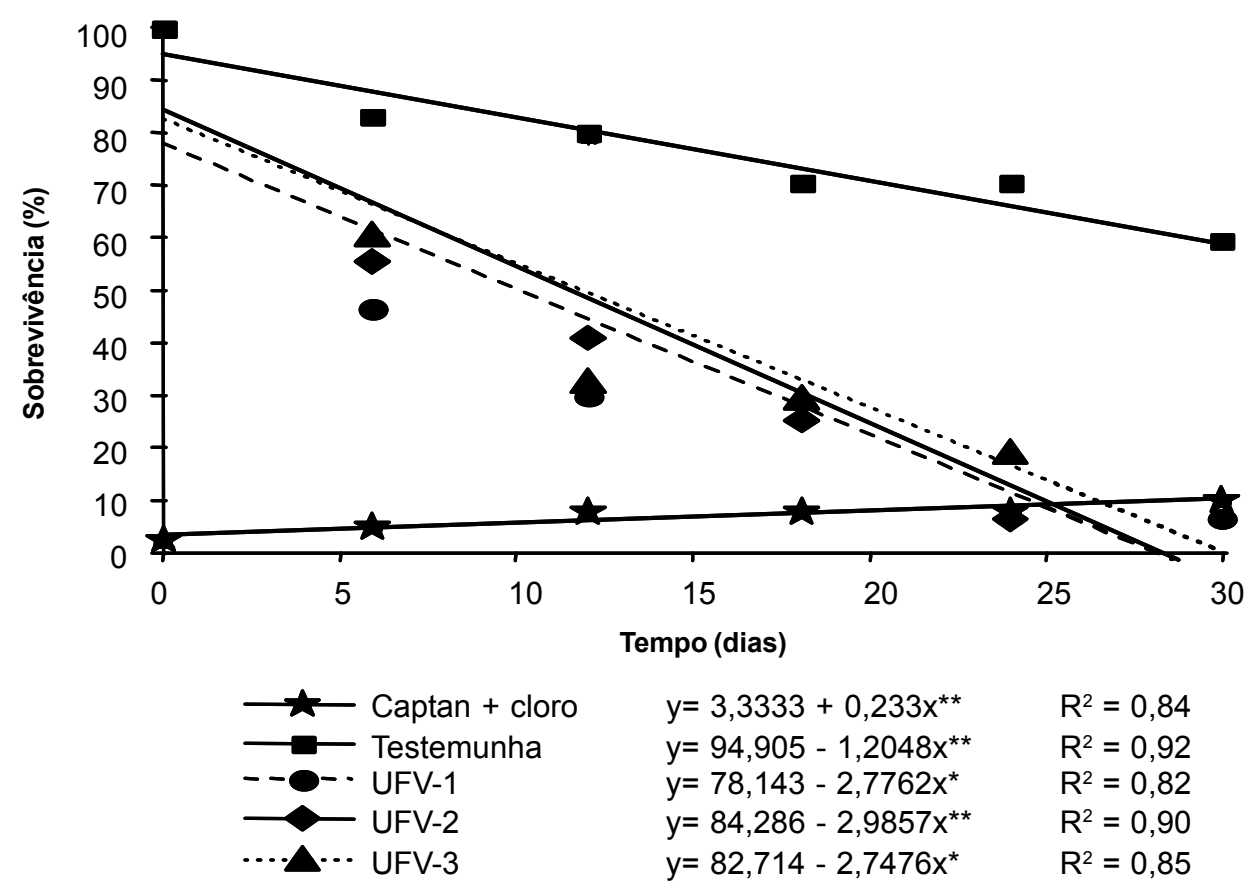

FIG. 2 - Sobrevivência de escleródios de Rhizoctonia solani AG1-1C (RH-15), quando tratados com suspensão conidial de Trichoderma longibrachiatum (UFV-1) e T. inhamatum (UFV-2 e UFV-3), sobre restos culturais de eucalipto (Eucalyptus spp.). * e** = Significativo pelo Teste F a 5\% e 1\% de probabilidade, respectivamente.

e, em cinco semanas, reduziram sua viabilidade em até $100 \%$. No presente trabalho, encontrou-se redução significativa na sobrevivência de escleródios de Rhizoctonia sp. tratados com suspensão conidial de T. longibrachiatum e T. inhamatum.

Pelos resultados obtidos, a aplicação de suspensão conidial de T. longibrachiatum (UFV-1) e T. inhamatum (UFV2 e UFV-3) sobre restos culturais de eucalipto, pode constituir uma alternativa para reduzir a sobrevivência de escleródios de $R$. solani. O tratamento com suspensão conidial de Trichoderma reduziu significativamente a viabilidade dos escleródios, equiparando-se ao tratamento com captan (1200 ppm) + hipoclorito de sódio (800 ppm de $\mathrm{Cl}_{2}$ ). Entretanto, nenhum dos antagonistas, ou mesmo a mistura de fungicida, afetou a sobrevivência de $R$. solani em folhas infetadas, o que mostra a importância de restos de poda de eucalipto como possíveis fontes de inóculo de $R$. solani e a necessidade das podas de limpeza e sua eliminação da área de multiplicação clonal.

Silveira et al. (1992) determinaram que a mistura de captan com hipoclorito de sódio teve efeito instantâneo sobre escleródios do patógeno. Errampalli \& Johnston (2001) também determinaram o efeito erradicante instantâneo que a imersão de escleródios de $R$. solani em solução de hipoclorito de sódio a $500 \mathrm{ppm}$ por $8 \mathrm{~min}$ ou $1.000 \mathrm{ppm}$ por $2 \mathrm{~min}$, proporcionam. Neste trabalho, constatou-se que a mistura captan + hipoclorito de sódio é efetiva no controle do patógeno durante, pelo menos, 30 dias. O ligeiro aumento na recuperação do fungo ao longo do tempo pode ser explicado pela remoção do princípio fungitóxico pela água de chuva no período experimental, e, também, pela alta degradabilidade do fungicida captan. Além disso, por se tratar de fungicida que atua por contato, não houve erradicação do micélio do patógeno que se encontrava no interior do tecido foliar.

Os resultados obtidos neste trabalho mostraram que os isolados de Trichoderma spp. não interferem na sobrevivência de $R$. solani em folhas infetadas de eucalipto, porém reduzem a viabilidade dos escleródios do patógeno, equiparando-se ao tratamento com fungicida (captan + cloro).

\section{REFERÊNCIAS BIBLIOGRÁFICAS}

ALFENAS, A.C., ZAUZA, E.A.V., MAFIA, R.G. \& ASSIS, T.F. Clonagem e Doenças do Eucalipto. Viçosa. Editora UFV. 2004.

BAIRD, R.E. Survival of Rhizoctonia solani AG-4 in residual peanut shells in soil. Plant Disease 77:973-975. 1993.

BEAGLE- RISTAINO, J.E. \& PAPAVIZAS, G.C. Biological control of Rhizoctonia stem canker and black scurf of potato. Phytopathology 75:560-564. 1985.

BENHAMOU, N. \& CHET, I. Hyphal interactions between Trichoderma harzianum and Rhizoctonia solani: ultrastructure and gold cytochemistry of the mycoparisitic process. Phytopathology 83:1062-1071. 1993.

BOOSALIS, M. \& SCHAREN, A.L. Methods for microscopic detection of Aphanomyces euteiches and Rhizoctonia solani and for isolation of Rhizoctonia solani associated with plant debris. Phytopathology 49:192-198. 1959.

BRUEHL, G.W. Soilborne Plant Pathogens. New York. Macmillan 


\section{A. Kunieda-Alonso et al.}

Publishing Company. 1987.

ERRAMPALLI, D. \& JOHNSTON, H.W. Control of tuber-borne black scurf (Rhizoctonia solani) and common scab (Streptomyces scabies) of potatoes with a combination of sodium hypoclorite and thiophanate-methil preplanting seed tuber treatment. Canadian Journal of Plant Pathology 23:68-77. 2001.

JAFFEE, B.A. Density-dependent parasitism in biological control of soil borne insects, nematodes, fungi and bacteria. Biocontrol Science and Technology 3:235-246. 1993.

MANIAN, S. \& MANIBHUSHANRAO, K. Influence of some factors on the survival of Rhizoctonia solani in soil. Tropical Agriculture 67:207-208. 1993.

MELO, I.S. Trichoderma e Gliocladium como bioprotetores de plantas. Revisão Anual de Patologia de Plantas 4:261-295. 1996.

MENZIES, J.D. The first century of Rhizoctonia solani. In: Parmeter, J.R. (Ed.). Rhizoctonia solani, Biology and Pathology. Berkeley. University of California Press. 1970. pp.69-92.

MUKHERJEE, P.K., MUKHOPADHYAY, A.N., SARMAH, D.K. $\&$ SHRESTHA, S.M. Comparative antagonistic properties of Gliocladium virens and Trichoderma harzianum on Sclerotium rolfsii and Rhizoctonia solani - its relevance to understanding the mechanisms of biocontrol. Journal of Phytopathology 143:275-279. 1995.

NAIKI, T. Population and survival of sclerotia of Rhizoctonia solani in soil. In: Parker, C.A., Rovira, A.D., Moore, K.J., Wong, P.T.W., \& Kollmorgen, J.F. (Eds.) Ecology and Management of Soilborne Plant Pathogens. St. Paul. American Phytopathological Society. 1985. pp.51-53.

PARK, D. Survival of microrganisms in soil. In: Baker, K.F. \& Snyder, W.C. (Eds.) Ecology of soil-borne plant pathogens. Berkeley. University of California Press. 1970. pp.82-98.

RUPPELL, E.G. Survival of Rhizoctonia solani in fallow field soil and buried sugarbeet roots at three dephts. Journal of Sugar Beet Research 28:141-153. 1991.

SHERWOOD, R.T. Physiology of Rhizoctonia solani. In: Parmeter, J.R. (Ed.). Rhizoctonia solani, Biology and Pathology. Berkeley. University of California Press. 1970. pp.69-92.

SILVEIRA, S.F., ALFENAS, A.C., MAFFIA, L.A. \& SUZUKI, M.S. Controle químico da queima de folhas e da mela de estacas de eucalipto, causadas por Rhizoctonia spp. Fitopatologia Brasileira 28:642-649. 2003.

SILVEIRA, S.F., FERREIRA, F.A. \& ALFENAS, A.C. Eficiência de produtos químicos para a erradicação de escleródios de Rhizoctonia solani em estacas de eucalipto. Fitopatologia Brasileira 17:223. 1992. (Resumo)

VENKATASUBBAIAH, P. \& SAFEEULLA, K.M. Studies on the viability of sclerotia of Rhizoctonia solani in the soil. Journal of Coffee Research 13:30-32. 1983. 